\title{
Candida biofilms and oral candidosis: treatment and prevention
}

\author{
David W. Williams, Tomoari Kuriyama, Sonia Silva, Sladjana Malic \& \\ Michael A. O. Lewis
}

In recent years, there has been a significant increase in the incidence of human fungal infections (60). A number of factors have been implicated with this increase, but it is generally accepted that the main influences relate to the more widespread provision of new medical practices, such as immunosuppressive therapy and use of broad spectrum antibiotics, and invasive surgical procedures such as solid organ or bone marrow transplantation. Infections may either be superficial, affecting the skin, hair, nails and mucosal membranes, or systemic, involving major body organs (95). The risk of systemic infection appears to be enhanced in cases where the individual is already colonized by Candida (71). With regard to superficial mucosal infections, the continued spread of HIV infection (29) and the more extensive use of inhaled steroids (36) have also played significant roles.

Of the fungi regarded as human pathogens, members of the genus Candida are amongst the most frequently recovered from disease. The Candida genus is a taxomomic grouping that was originally used to define 'yeast-like' organisms that were not considered to have a sexual reproductive life cycle. Candida contains over 350 heterogeneous species, but only a minority of these have been implicated in human disease (Table 1). Infections caused by Candida are collectively referred to in the plural as candidoses (singular candidosis) or candidiases (singular candidiasis). Both terms are used in the literature although candidosis is preferred to candidiasis by many due to the '-osis' part of the word being consistent with the nomenclature used for other fungal infections.

Of the Candida species isolated from humans, Candida albicans is the most prevalent in both health and disease. It is generally accepted that commensal carriage of this species occurs in approximately $50 \%$ of individuals $(81,107)$, although figures do vary depending on the population examined. Mycological studies have shown that $C$. albicans represents over $80 \%$ of isolates from all forms of human candidosis (85). However, the so-called non-Candida albicans Candida species are increasingly recognized as important agents of human infection $(41,46,55,72)$. The apparently increased involvement of non-Candida albicans Candida species in human candidoses may partly relate to improvements in diagnostic methods, such as the use of primary agars with the ability to differentiate species, and the introduction of molecular techniques in the routine diagnosis of fungaemia (64). However, the increased prevalence of non-Candida albicans Candida species in disease could also be a reflection of the inherently higher level of antifungal drug resistance in some nonCandida albicans Candida species (39) compared with $C$. albicans, as this would promote their persistence, possibly to the detriment of C. albicans, in mixed-species infections treated with traditional antifungal agents.

Candidoses have been recognized throughout human history and are often described as being 'diseases of the diseased', reflecting the opportunistic pathogenic nature of Candida. Whilst Candida species are generally regarded as harmless members of the healthy commensal microflora of humans, infection can arise if a colonized individual becomes immunocompromised.

Candida species have been encountered in a wide spectrum of diseases, and almost all human body organs can become infected (79). Systemic infections are rare, but are serious when they do occur, with 
Table 1. Candida species associated with human infection

\begin{tabular}{lc}
\hline Candida species* & Reference \\
\hline Candida albicans & $(11)$ \\
Candida dubliniensis & $(114)$ \\
Candida parapsilosis & $(115)$ \\
Candida tropicalis & $(41)$ \\
Candida glabrata & $(63)$ \\
Candida kefyr & $(23)$ \\
(pseudotropicalis) & $(6)$ \\
Candida lusitaniae & $(104)$ \\
Candida krusei & $(71)$ \\
Candida guilliermondii & $(44)$ \\
Candida utilis & $(108)$ \\
Candida lipolytica & $(56)$ \\
Candida famata & $(52)$ \\
Candida haemulonii & $(113)$ \\
Candida rugosa & \\
\hline
\end{tabular}

*The list is an indication of the typical Candida species that have been associated with human infection but is not intended to be comprehensive of all pathogenic species.

mortality rates of up to $60 \%(22,62)$. The incidence of systemic fungal infection has increased in recent decades, although exact figures are difficult to ascertain as most are only diagnosed following autopsy. However, in the past 10 years, a fivefold increase in candidaemia has been reported (14), and the current incidence of candidaemia per 1,000 admissions in Europe ranges from 0.17 to 20 depending on the country and patient group studied (60). Particularly susceptible patients are those suffering from leukaemia or recipients of haematopoietic stem cell transplants (i.e. bone marrow transplants) (85). However, the vast majority of infections remain superficial, affecting moist mucosal membranes, particularly of the vagina and oral cavity (Fig. 1). More recently, it has been suggested that Candida species may be causative agents in some diseases of the mouth other than candidosis, including oral cancer (109), burning mouth syndrome (102), taste disorders (98) and endodontic disease (74), although the basis of these associations remains uncertain.

There is little evidence for yeast involvement in periodontal disease, with bacterial species such as Porphyromonas gingivalis, Tannerella forsythia and Aggregatibacter actinomycetemcomitans being the most frequently associated periodontal pathogens (54). There have been some reports in the literature linking the presence of Candida with the clinical condition of linear gingival erythema that is occasionally seen in HIV-infected patients $(40,119)$. However, a causative role for Candida has not been
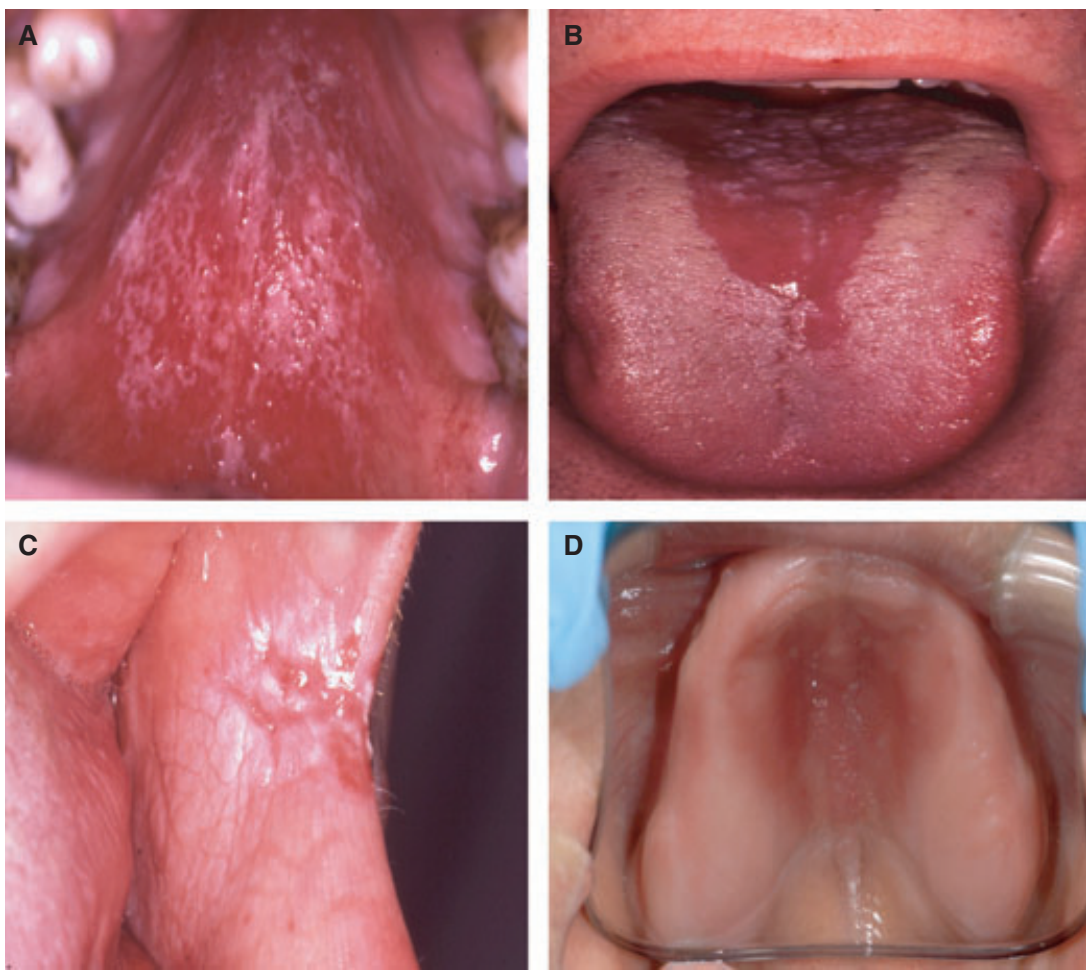

Fig. 1. Clinical presentation of primary oral candidosis: (A) pseudomembranous candidosis, (B) acute erythematous candidosis, (C) chronic hyperplastic candidosis, and (D) chronic erythematous candidosis. 
confirmed and the condition is rarely observed today, possibly due to the frequent use of systemic antifungal agents in these patients.

Interestingly, whilst the microflora of periimplantitis resembles that of chronic periodontitis, Candida has been recovered from $55 \%$ of peri-implant lesions and appears to be absent at healthy implant sites (61). However, the aetiological involvement of Candida in peri-implantitis requires further longitudinal studies.

\section{Virulence factors of Candida}

Infection models of candidosis in animals suggest that C. albicans is the most pathogenic species, and in vitro investigations indicate that it also expresses higher levels of putative virulence factors compared with other Candida species. Several potential virulence factors have been proposed in the pathogenicity of Candida species (Table 2), with adhesion to host surfaces, secretion of proteinases and hyphal formation apparently the most significant.

\section{Adherence of Candida to host surfaces}

Adherence of Candida to host surfaces is required for initial colonization and contributes to persistence of the organism within the host. Candida cells adhere to several host cell types, including epithelial, endothelial and phagocytic cells. Among the many adhesins expressed by C. albicans, agglutinin-like sequence proteins have been implicated in pathogenesis and biofilm formation (78). These cell wall-bound adhesins bind to diverse mammalian peptide ligands, causing cellular aggregation through homotypic adhesion, and also co-aggregate with other microbial pathogens to mediate polymicrobial infections. Candida can adhere to the surface of medical devices, in particular denture acrylic and silicone soft liners, which often promotes biofilm formation.

\section{Secretion of hydrolytic enzymes by Candida}

Candida species secrete several hydrolytic enzymes associated with pathogenicity, including secreted aspartyl proteinases, phospholipases, lipases, phosphomonoesterase and hexosaminidase (80). Of these enzymes, the secreted aspartyl proteinases have attracted most interest and are widely considered to be central to the development of Candida infection. In contrast with other types of proteinases, secreted aspartyl proteinases show proteolytic activity only under acid conditions $(\mathrm{pH}<4.0)$. Importantly for oral infection, the environment under a removable denture is acidic, which provides conditions suitable for both production and activity of secreted aspartyl proteinases. Secreted aspartyl proteinases are only produced by certain Candida species, with C. albicans secreting nine distinct aspartyl proteinases, often at much higher levels compared with other species. Interestingly, strains of C. albicans isolated from clinically apparent oral candidosis have been

Table 2. Virulence factors associated with Candida and oral candidosis

\begin{tabular}{ll}
\hline Virulence factor & \multicolumn{1}{c}{ Effect } \\
\hline Adherence to host surfaces & Promotes retention in the mouth \\
- Relative cell-surface hydrophobicity & - Non-specific adherence process \\
- Cell surface adhesin molecules & - Specific adherence mechanisms \\
Evasion of host defence mechanisms & Promotes retention in the mouth \\
- High-frequency phenotypic switching & - Antigenic modification through frequent cell-surface changes \\
- Hyphal development & - impairs phagocytosis \\
- Secreted aspartyl proteinase production & - Secretory IgA destruction \\
- Binding of complement molecules & - Antigenic masking \\
Invasion and destruction of host tissue & Enhances pathogenicity \\
- Hyphal development & - Promotes invasion of oral epithelium \\
- Secreted aspartyl proteinase production & - Host cell and extracellular matrix damage \\
- Phospholipase production & - Damage to host cells \\
\hline
\end{tabular}


shown to produce higher levels of secreted aspartyl proteinases compared with strains obtained from carriers with no mucosal signs (58). These findings suggest that strains of $C$. albicans that are actively involved in candidosis could be inherently more virulent than commensal strains, possibly by being able to upregulate secreted aspartyl proteinase gene expression. In contrast, there is no conclusive evidence that proteinase activity is always associated with infection, and this probably reflects the multifactorial nature of Candida infections (80). Phospholipases hydrolyse one or more ester linkages of glycerophospholipids. Phospholipase activity has been demonstrated for many fungal pathogens, including Candida species. It has been reported that the phospholipase activity is enhanced when hyphae are in direct contact with host tissue.

\section{Morphological transition of Candida}

Candida species, in particular C. albicans, can exhibit morphological alternation from yeast, pseudohyphal and hyphal forms, depending on environmental conditions. Hyphae are believed to play an important role in tissue and biomaterial invasion, and in vitro research has shown that $C$. albicans hyphal mutants and non-C. albicans strains lacking hyphal formation exhibit lower ability to invade tissue compared with wild-type C. albicans strains (50). Candida hyphae also demonstrate increased adherence properties (53, $80,103)$ and greater resistance to phagocytosis compared with yeast. Thus hyphal formation is considered to be significant to the pathogenicity of Candida.

\section{Candida biofilms and infection}

Biofilms can be defined as communities of microorganisms, often attached to a surface and encased within an extracellular polysaccharide matrix that is produced by the microorganisms (25). The biofilm state is the preferred mode of growth of microorganisms in natural environments (24), and recent reports have linked biofilms with over $65 \%$ of hospital-acquired infections $(28,51)$. It has also been suggested that Candida strains with a high ability to form biofilms are generally more virulent than others $(79,104)$. The explanation for this is likely to be multifactorial and relate to the differences observed between biofilm cells and their free-living or planktonic counterparts. Indeed, it is now known that significant phenotypic differences occur between biofilm and planktonic lifestyles (8, 28, 73, 91, 92). Perhaps the most important of these are those factors that relate to the promotion, persistence and virulence of the organisms within the host environment. A recent investigation of candidaemia highlighted the importance of biofilms in infection, with higher mortality rates evident when a Candida biofilm was present (116).

In the oral cavity, not only will adherent biofilm cells be protected from the normal mechanical flushing action of saliva and gingival crevicular fluid, but the biofilm itself is a defensive barrier against penetration of host immune factors and administered antimicrobials $(43,121)$. Candida biofilms were first shown to exhibit resistance to antifungals by Hawser \& Douglas (43), and this has been reported by numerous other researchers since $(19,92)$. The exact mechanism of biofilm resistance to antifungals remains unclear, but it is probably multifactorial. The extracellular polysaccharide of the biofilm could serve as an inhibitor to diffusion of an antimicrobial agent or ionically bind the drug as it diffuses through the biofilm, thereby effectively reducing its 'bioavailability' $(3,8)$. A feature of multilayered biofilms is the reduced activity and growth rates of cells that are in areas of limited exposure to required gases and nutrients, and it could readily be envisaged how these cells would be less susceptible to an antimicrobial that relies on inhibiting biochemical pathways associated with actively growing cells. These cells could represent the 'persister cells' that have been suggested to be the resistant phenotype within a biofilm community (59). Conversely, other studies have demonstrated that biofilm resistance mechanisms are actually not completely dependent on changes in growth rates (7), and may be the result of upregulation of particular genes by biofilm cells. Indeed, the genes encoding ATP-binding cassette (ABC) transporter proteins that are particularly associated with azole drug resistance by efflux pump mechanisms in C. albicans have been shown to be upregulated in biofilms $(69,73)$.

Involvement of Candida biofilms in human infection is well recognized, particularly when occurring on biomaterials used for implantable medical devices (Fig. 2). Away from the oral cavity, biofilms of Candida on the silicone rubber of artificial voice box prostheses in laryngectomized patients have been identified as a major cause of their failure. Urinary tract infection by Candida in catheterized patients is associated with biofilm formation on the inner lumen of the catheter, and other infections including those of prosthetic heart valves and replacement joints have also been linked with Candida biofilms (18, 49, 96). Candida colonization of intravascular catheters 

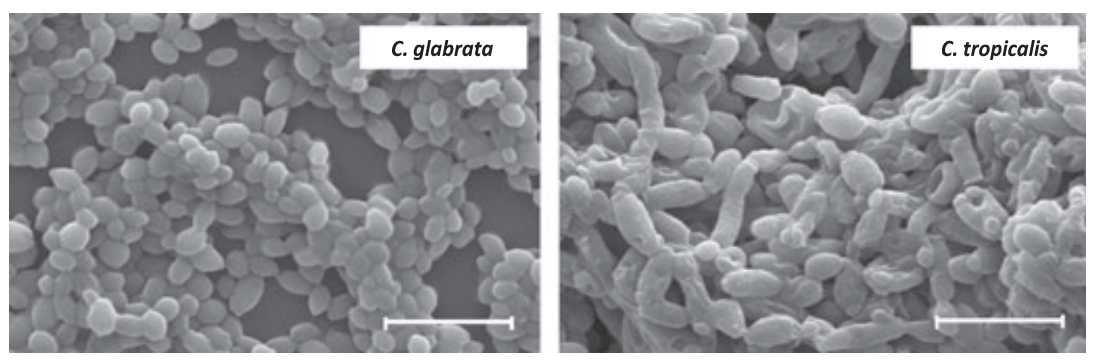

Fig. 2. Scanning electron microscopy of Candida biofilms formed on silicone rubber surfaces for $48 \mathrm{~h}$. The scale bar in the images corresponds to $10 \mu \mathrm{m}$. Original magnification, $\times 5,000$.

is a major cause of catheter-related infections, and has the highest associated mortality rate of such infection (26). Candidal biofilm formation within haemodialysis and peritoneal dialysis catheters is frequent, with up to $20 \%$ infected (90). Such biofilms are responsible for candidaemia or Candida peritonitis in patients receiving these treatments.

In terms of oral candidosis, the presence of an oral prosthesis, most frequently an upper denture, is a major predisposing factor for oral candidosis (Table 3). Candida are highly adherent to polymethylacrylate, which is the base material of dentures, and recent studies have demonstrated that Candida can also exploit the presence of microfissures and cracks within the material, thus facilitating retention and biofilm promotion (120). An increased surface roughness will also similarly aid colonization of the denture by Candida. The formation of biofilms on denture surfaces is promoted by poor oral hygiene, and practices such as failure to remove the denture whilst sleeping and poor denture cleansing are strongly associated with denture biofilms. Further-

Table 3. Local and systemic host factors with associated oral candidosis

\begin{tabular}{lc}
\hline Predisposing host factor & Reference \\
\hline Local host factor & \\
Wearing dentures & $(17)$ \\
Steroid inhaler use & $(36,37)$ \\
Reduced salivary flow & $(89)$ \\
Nutrition & $(100)$ \\
Systemic host factors & \\
Extremes of age & $(124)$ \\
Endocrine disorders, & $(111)$ \\
e.g. diabetes & \\
Immunosuppression & \\
Receipt of broad- & $(29)$ \\
spectrum antibiotics & $(112)$ \\
\hline
\end{tabular}

more, the abiotic surface of the denture means that the ability to remove adherent microbes through selfrenewal of surface layers does not occur as would be encountered on living mucosa. In addition, the static conditions with respect to lack of salivary flow under the fitting surface of the denture are also a contributory factor for biofilm formation, as mechanical removal of microorganisms by the flushing action of saliva is limited.

The form of oral candidosis that is most directly associated with a Candida biofilm is chronic erythematous candidosis, where colonization of the denture surface in the form of a biofilm is an integral component of the infection. In chronic erythematous candidosis, the fitting surface of the denture acts as a reservoir of infectious Candida cells, which, given their close proximity to the palatal mucosal surface, are suitably positioned to cause local infection. Normally the mucosal surface provides an effective barrier to infection; however, an ill-fitting denture may cause frictional irritation of the palatal mucosa and this facilitates invasion of Candida into the superficial layers of the epithelium. On occasions, a denture soft liner may be used to cushion the hard acrylic material of the denture against the mucosa. The soft liner serves to reduce friction and irritation, and to distribute the load exerted by the denture on the mucosa. Unfortunately, silicone rubber (the most frequently employed material for soft liners) is also a surface that Candida can readily colonize and actually invade (16). Therefore, even when use of a silicone rubber soft liner has improved the fit of a denture, the clinical signs of denture stomatitis may not always disappear. This is particularly the case for patients whose denture cleansing regimens are poor. In such instances, maintenance of oral hygiene is vital, and antifungal agents might be considered as an adjunct in the management strategy. There have been attempts to incorporate antifungal agents directly into the soft liner material, but difficulties in maintaining an adequate release of the agent over sufficiently long periods have frequently been encountered (38). 

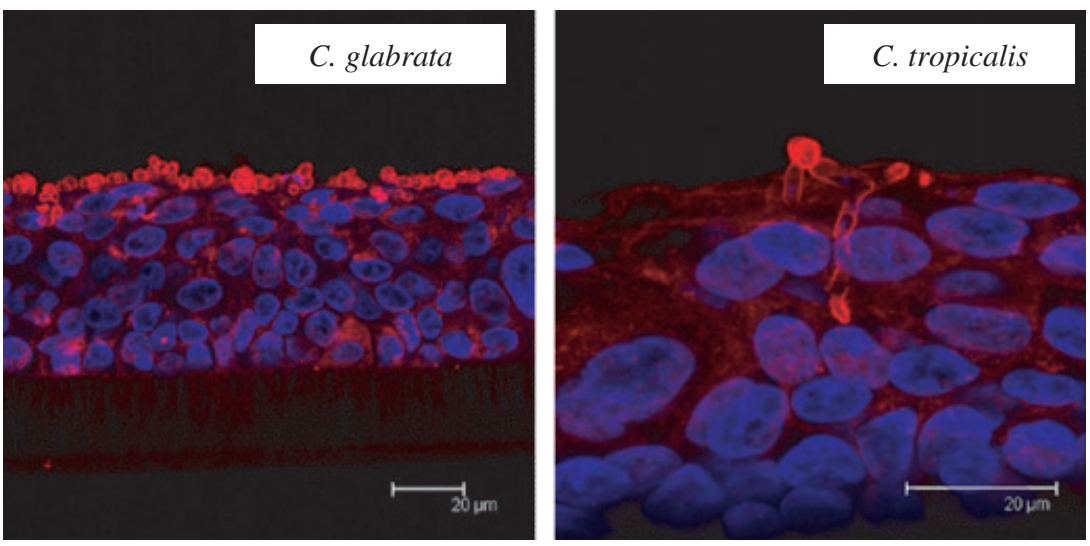

Fig. 3. Confocal laser scanning microscopy images of (A) Candida glabrata and (B) Candida tropicalis colonizing and invading human oral epithelium after $24 \mathrm{~h}$ incubation. Candida yeast and filaments are shown in red, and the nuclei of the epithelial cells appear blue.

The wearing of a denture is also a predisposing factor to other forms of oral candidosis, such as hyperplastic candidosis and angular cheilitis (2). Whilst these types of oral candidosis occur at sites away from the denture biofilm, it is probable that the increase in Candida numbers resulting from the presence of a denture is a major contributory factor in these infections (1).

Most natural host surfaces such as the oral mucosa have major advantages compared with implanted biomaterials and other non-shedding surfaces in preventing Candida colonization and biofilm formation. Clearly, the innate immune response of the host will be effective within the oral mucosa, and, as previously mentioned, the fact that the oral epithelium is continually replenished means that, in order to colonize the oral mucosa, Candida must be present in the mouth in sufficient numbers and with a high enough growth rate to allow their continued persistence. In healthy individuals, candidal biofilms are therefore not generally seen on the palatal or buccal mucosa, although low-level colonization will be detected in cases of commensal carriage. In the event of host debilitation causing an ecological shift in favour of Candida growth, candidal biofilms may develop on the mucosa itself (Fig. 3) (27). Indeed, in cases of pseudomembranous candidosis and hyperplastic candidosis, multilayered growth of Candida adhering to the mucosal surface can be seen using histological staining methods applied to either mucosa smears or biopsy sections (Fig. 4).

\section{Candida biofilm formation}

As described above, the presence of Candida biofilms can play a significant role in clinical infection because of their resilience and resistance to normal host removal mechanisms and also antimicrobial therapy.

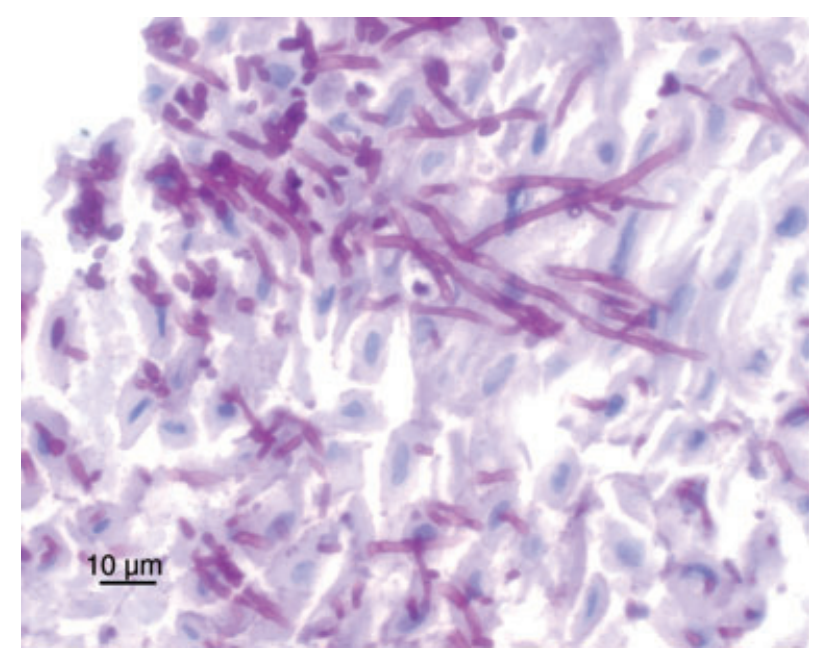

Fig. 4. Periodic acid Schiff-stained tissue section of chronic hyperplastic candidosis showing tissue invading Candida hyphae (purple-stained filaments).

In order to adequately treat and prevent these infections, it is therefore first necessary to understand the processes involved in candidal biofilm formation and growth, which could then lead to the identification of suitable targets for therapy.

Candida biofilm formation and infection is a staged process comprising (i) adherence to the surface, (ii) colonization, proliferation and invasion, and (iii) detachment of biofilm cells to promote colonization and infection of distal sites. Altered gene expression accompanies development of the biofilm, and such changes can be detected soon after initial attachment to the surface (75). In the case of C. albicans, biofilm formation has been reported to be associated with the upregulation of genes involved in adherence (such as agglutinin-like sequence genes and hyphal wall protein 1; Hwpl) (78) and also those genes involved in amino acid biosynthesis and metabolism (126).

The initial stage of adhesion of Candida to host surfaces occurs through the combined effects of 
non-specific and specific adherence mechanisms. One key non-specific force in adhesion is the hydrophobic attraction of candidal surface molecules to the intended site of attachment. Normally the surface of a biomaterial will become rapidly coated in proteinaceous components derived from conditioning fluids such as the constituents of saliva. Together with electrostatic forces, a net attraction will be generated that brings about the necessary close proximity between the microorganism and the surface to allow specific adhesion mechanisms to occur, and several specific Candida adhesin molecules and host receptors have been described. In the case of Candida, it is usually the yeast form that is involved in initial adherence (24).

Once a firm attachment of the yeast to the surface has become established through specific adhesins and host receptors, proliferation of Candida may occur, with growth of the yeast and generation of filamentous extensions. It is believed that ultimately, hyphae provide the greatest component of the biofilm biomass, with the yeast providing a base layer for their attachment. In vitro studies using confocal laser scanning microscopy analysis of C. albicans biofilm formation on reconstituted human oral epithelium have shown the importance of hyphal production in the invasion process $(13,67)$. Cross-linking between hyphal extensions mediated by interaction of $\mathrm{Hwpl}$ and agglutinin-like sequence surface proteins (78) might provide additional stability to the biofilm structure. Candida species produce extracellular polysaccharide to varying degrees, with large quantities present in biofilms of C. albicans and lower amounts for Candida glabrata (83). The extracellular polysaccharide matrix produced by C. albicans biofilms, whilst composed primarily of carbohydrates, also includes proteins, hexosamine, phosphorus and uronic acid $(4,8)$.

The extent of Candida proliferation is determined by many factors, including the ability of the host to elicit innate defensive mechanisms, the inherent competition for nutrients and space provided by other members of the oral microflora, and regulation of biofilm formation by the Candida cells themselves. There is now clear evidence for the presence of cellto-cell signalling molecules in bacterial biofilms that serve as biofilm density-dependent regulators. These chemicals are frequently termed 'quorum sensing molecules', and include the acyl homoserine lactones and small peptide regulators produced by Gramnegative and Gram-positive bacteria, respectively. The role of quorum sensing molecules in biofilms is to regulate expression of a variety of genes that can coordinate not only growth rate, but biofilm detachment, virulence, antimicrobial resistance and even induction of host cytokines. In the case of Candida biofilms, two quorum sensing molecules have been described, namely, farnesol (3,7,11-trimethyl-2,6,10dodecatriene-1-ol) and tyrosol (2-[4-hydroxyphenyl] ethanol), and the concentration and effects of these molecules on biofilms has been found to be timedependent. The recognition of farnesol production by Candida was the first description of a quorum sensing molecule in a eukaryotic system. Farnesol has been shown to be an inhibitor of hyphal development in C. albicans $(47,92,106)$, and its accumulation in mature biofilms is thought to be responsible for inducing the release or detachment of yeast from the biofilm (77). Recently, it was reported that C. albicans also secretes dodecanol, which is a chemical inhibitor of the yeast-to-hyphal transition (68). In contrast, tyrosol appears to be an accelerator of candidal filamentation under suitable conditions $(21,47)$, and plays an important role in proliferation of the filamentous form after the adherence phase and through to intermediate biofilm stages (5).

\section{Clinical presentation of oral candidosis}

Oral candidosis is not a single clinical entity, but is recognized to occur as four distinct primary forms. These include two transient types, namely pseudomembranous candidosis and acute erythematous candidosis, and two persistent forms, termed chronic erythematous candidosis and chronic hyperplastic candidosis. In addition, the long-term immunosuppressive state associated with HIV infection/AIDS and the more widespread administration of immunosuppressive drugs has resulted in a prolonged form of pseudomembranous candidosis, which may be referred to as chronic. Candida has also been implicated in angular cheilitis and median rhomboid glossitis. Each type of infection is associated with characteristic clinical signs and symptoms that are influenced by a range of predisposing factors (Table 3 ).

\section{Pseudomembranous candidosis}

Pseudomembranous candidosis is synonymous with the term 'oral thrush', and is reported in neonates and the elderly at rates of $5-10 \%$ (101). The infection is characterized by the presence of superficial white plaques that are easily removed by gentle rubbing of the lesion (Fig. 1A) (99). The ability to remove these 
plaques is a diagnostic feature that differentiates pseudomembranous candidosis from other forms of white patch lesions of the oral mucosa. Histological examination of the plaques reveals fungal elements in the form of yeast and filamentous forms, together with epithelial cells.

\section{Acute erythematous candidosis}

This condition is often referred to as 'antibiotic sore mouth', as it tends to develop following a reduction in the levels of the bacterial component of the oral microflora after the receipt of broad-spectrum antibiotics. A decrease in bacterial numbers results in reduced microbial competition for Candida in terms of nutrition and adherence sites. The clinical signs and symptoms of acute erythematous candidosis are therefore a direct consequence of an ecological shift in the normal homeostatic balance of the microbial community. Acute erythematous candidosis presents as a painful reddened lesion, and although the palate or buccal mucosa may be involved, the most common site of infection is the dorsum of the tongue (Fig. 1B). Cessation of antibiotic therapy results in a return to normal levels of bacteria, which subsequently resolves the candidosis without intervention. Concomitant use of steroid therapy, particularly in inhaler form, is an additional contributing factor, as this can create a localized area of immune suppression within the mucosa that permits overgrowth of Candida.

\section{Chronic hyperplastic candidosis}

This form of candidosis characteristically presents as a thickened white plaque, most frequently at the commissure region of the mouth or on the dorsum of the tongue (Fig. 1C). Of particular concern with this form of infection is the potential for the development of squamous cell carcinoma at lesional sites, although the role of Candida in the process of malignant change remains unclear $(109,122)$. Two clinical types of hyperplastic candidosis have been described based on the appearance of the lesion. Homogeneous hyperplastic candidosis is described as having smooth white lesions that are notably distinct from those of heterogeneous hyperplastic candidosis in which areas of erythema occur resulting in a nodular, speckled appearance. It has been suggested that heterogeneous lesions have a greater likelihood of malignant transformation (12, 94). In contrast to pseudomembranous candidosis, the white patch lesions of hyperplastic candidosis do not rub off with gentle rubbing. Hyperplastic candidosis can only be diagnosed by histopathological examination of lesional biopsy material, which reveals candidal hyphae invading the epithelium and an underlying chronic inflammatory cell infiltrate (125). Uncertainty remains over whether candidal invasion is the primarily ecological factor of hyperplastic candidosis, or whether Candida infection is secondary to the formation of an altered epithelium. Almost all patients with hyperplastic candidosis are smokers.

\section{Chronic erythematous candidosis}

Commonly known as Candida-associated denture stomatitis, chronic erythematous candidosis presents as a reddening of the mucosa beneath the fitting surface of a denture (Fig. 1D). The infection may develop under any acrylic denture or intra-oral appliance, but is almost exclusively encountered on palatal tissues. Principle host factors associated with this condition are inadequate oral hygiene, failure to remove dentures whilst sleeping, or poor denture fit (32). Chronic erythematous candidosis is the most prevalent form of oral candidosis, with up to $75 \%$ of denture wearers having clinical signs of this condition, although the sufferer is often unaware of the presence of infection (9).

\section{Angular cheilitis}

This condition presents as erythematous lesions at one or more, or usually both of the angles of the mouth. In addition to Candida, the spectrum of microorganisms recovered from this condition includes Staphylococcus aureus and streptococcal species, either alone or in combination. Therefore, the exact role that Candida itself plays in angular cheilitis remains uncertain (110). Often, angular cheilitis involving Candida occurs in patients with a pre-existing primary form of oral candidosis, most frequently chronic erythematous candidosis. The increased level of Candida within the mouth of such patients is most likely to be the major contributing factor.

\section{Other oral candidoses}

Median rhomboid glossitis is a chronic mucosal condition that, as its name implies, characteristically presents as a symmetrically shaped lesion on the midline of the dorsum of the tongue. Candida can often be recovered from the surface of the lesion, has 
and is thus implicated in the aetiology. Furthermore, resolution of the condition following provision of systemic antifungal therapy supports the role of Candida in the infection. As with other forms of oral candidosis, tobacco smoking and steroid inhaler use are recognized predisposing factors.

Chronic mucocutaneous candidosis is a rare condition in which a range of chronic Candida infections of mucous membranes, skin and nails are encountered. The principle predisposing factor for chronic mucocutaneous candidosis is congenital impaired cellular immunity against Candida.

\section{Management of oral candidosis}

\section{Principles of treatment}

Successful management of patients with oral candidosis requires identification, and where possible correction, of the specific underlying predisposing factors in an individual patient. Without this recognition, subsequent treatment using antifungal therapy may only result in the temporary relief of infection, with relapses inevitably following. Instructions should be provided on appropriate oral hygiene practices. Use of steroid inhalers should be coupled with rinsing the mouth with water after administration. All patients should be advised on the importance of reduction or cessation of any smoking habits. As described below, oral hygiene practices are also essential in removal of candidal biofilms on host surfaces and oral prostheses.

Any identified nutritional deficiency should be corrected, and advice provided on dietary habits such as appropriate carbohydrate intake. However, despite these interventions, situations arise in which the underlying cause cannot be resolved, such as HIV infection or immunosuppressive therapy following organ or bone marrow transplant. In these circumstances, treatment of oral candidosis is based on the use of antifungal therapy. Details on antifungal agents are provided below, and Table 4 shows the typical antifungal drugs and the treatment regimes used specifically for oral candidosis.

\section{Antifungal agents}

Relatively few antifungal drugs are available when compared to the range of antibiotics that have been produced, which probably reflects both the relatively recent recognition of the importance of fungal infections in humans and the difficulty involved in developing an agent with activity against a eukaryotic cell type without problems of associated host cell toxicity. Antifungal drugs are classified according to their mode of action: (i) disruption of fungal cell membranes, as seen with the polyene antifungals (nystatin and amphotericin), (ii) inhibition of ergosterol synthesis, exemplified by the azole group of antifungals (fluconazole and itraconazole), (iii) inhibition of $\beta$-1,3-D-glucan synthesis (echinocandin antifungals), and (iv) induction of incorrect RNA synthesis and interference with DNA replication (5-fluorocytosine).

Polyene antifungals exert their fungicidal activity by inducing cell membrane porosity following interaction with the ergosterol component of the membrane, with the subsequent effect of loss of cytoplasmic content. Polyenes have a broad spectrum of antifungal activity, but, due to their poor absorption through the gut, their use in treatment of oral candidosis is extremely limited. However, in view of the fact that these agents are not absorbed, their safety profile is good. A specific role for the topical use of these agents is in cream format for the treatment of chronic erythematous candidosis. Despite wide use over several decades, the actual incidence of resistance of Candida to polyenes is rare, but can sometimes arise through a reduction in the ergosterol content of cell membranes (105).

Azole antifungals are fungistatic through interference with the fungal enzyme lanosterol demethylase, which is a key enzyme in the biosynthesis of ergosterol. Both fluconazole and itraconazole are well absorbed through the gut, which means that oral administration is an effective means of systemic delivery. Furthermore, the effects of fluconazole in the oral cavity are enhanced as it is secreted in saliva at levels equivalent to those achieved in the blood. Fluconazole is the agent of first choice for all forms of oral candidosis apart from chronic erythematous candidosis. The clinical effectiveness of agents that can only be delivered topically, such as amphotericin or nystatin, is limited due to problems in maintaining sufficient levels of drug at the site of infection. The taste of topical agents stimulates salivary secretion, which rapidly dilutes and removes the antifungal agent from the mouth. In view of this, their clinical use is limited. Fluconazole has a good safety profile when given systemically, with few contra-indications or side effects. Important interactions occur with coumarin anticoagulants and sulfonylurea antidiabetic agents. Acquired resistance to azole antifungals has emerged in recent years, and certain Candida species are also inherently resistant to these agents. 
Table 4. Recommended antifungal agents for treatment of oral candidosis

\begin{tabular}{|c|c|c|c|c|c|}
\hline & PMC & AEC & CEC & $\mathrm{CHC}$ & Typical adult dose \\
\hline \multicolumn{6}{|l|}{$\begin{array}{l}\text { Topical } \\
\text { administration }\end{array}$} \\
\hline Nystatin & & & Yes & & $\begin{array}{c}\text { one lozenge: } \\
100,000 \text { units } \\
\text { q.i.d. } \times 7-14 \text { days } \\
\text { Suspension: } 500,000 \\
\text { units by rinse and } \\
\text { swallow q.i.d. } \times 7- \\
14 \text { days }\end{array}$ \\
\hline Amphotericin & & & Yes & & $\begin{array}{l}\text { one lozenge }(10 \mathrm{mg}) \\
\text { q.i.d. } \times 10-15 \text { days }\end{array}$ \\
\hline Miconazole & & & Yes & & $\begin{array}{c}\text { Oral gel }(24 \mathrm{mg} / \\
\mathrm{ml}) ; 5-10 \mathrm{ml} \text { q.i.d. } \times \\
7-14 \text { days }\end{array}$ \\
\hline Clotrimazole & & & Yes & & $\begin{array}{l}\text { one lozenge }(10 \mathrm{mg}) \\
\text { five times per day } \times \\
7-14 \text { days }\end{array}$ \\
\hline \multicolumn{6}{|l|}{$\begin{array}{l}\text { Systemic } \\
\text { administration }\end{array}$} \\
\hline Ketoconazole & Yes & Yes & & Yes & $\begin{array}{c}200-400 \mathrm{mg} / \text { day } \times \\
7-14 \text { days }\end{array}$ \\
\hline Fluconazole & Yes & Yes & & Yes & $\begin{array}{c}100 \mathrm{mg} / \text { day } \times 7- \\
14 \text { days }\end{array}$ \\
\hline Itraconazole & Yes & Yes & & Yes & $\begin{array}{l}200 \mathrm{mg}(20 \mathrm{ml}) \text { sus- } \\
\text { pension by rinse and } \\
\text { swallow without } \\
\text { food q.i.d. } \times 7- \\
14 \text { days } 200 \mathrm{mg} / \\
\text { day (capsules taken } \\
\text { with food) } \times 2- \\
4 \text { weeks }\end{array}$ \\
\hline
\end{tabular}

PMC, pseudomembranous candidosis; AEC, acute erythematous candidosis; CEC, chronic erythematous candidosis; CHC, chronic hyperplastic candidosis. q.i.d., four times per day.

Other antifungal agents are available and these may be more frequently used in hospitalized patients.

Several mechanisms of azole resistance have been reported including (i) an alteration in the chemical structure of the demethylase enzyme, (ii) removal of the azole from the cell by multidrug transporter pumps, and (iii) compensation by other sterol synthesis enzymes in membrane biosynthesis. Even in the absence of a defined resistance mechanism, the in vitro susceptibility of a given Candida strain often does not correlate with the subsequent clinical outcome for patients with oral candidosis. One possible explanation for this could relate to the phenotypic differences described above for planktonic and biofilm cultured cells, as it is the former that are most frequently used for in vitro antifungal susceptibility testing.

\section{Management of candidal biofilms}

As described previously, the presence of candidal biofilms reduces the likelihood of removal of organisms by host defence mechanisms and antifungal agents. Thus appropriate management of biofilms is essential. There is no single approach that can be used to specifically counter candidal biofilms, and a variety of mechanical and chemical methods to improve oral hygiene are generally adopted. Ideally an 'anti-biofilm' approach will prevent development of the biofilm in the first instance, as well as being effective against established biofilms.

Standard oral hygiene practices including toothbrushing and the use of mouthwashes are important 
tools in oral biofilm removal. Toothbrushing offers a physical means to combat biofilms (97), but may be limited to accessible sites within the oral cavity and can have deleterious effects on acrylic denture surfaces if abrasive toothpastes are used. In such cases, the resulting roughened acrylic surface could, in theory, be more conducive to subsequent biofilm formation. It has been suggested that mechanical toothbrushing may offer an advantage over manual toothbrushing by having an additional physical influence on biofilms at sites inaccessible to the toothbrush bristles, such as interproximal regions. Potential benefits of sonication include possible cavitation of surrounding fluids and generation of shear forces, which then disrupt the biofilm, although its clinical value remains uncertain (45). The potential antifungal effects of such shear forces on Candida are as yet not known. Nevertheless, as dental plaque contains yeast, toothbrushing will serve to reduce the level of Candida in the mouth and also maintain normal levels of mucosal resistance to fungal infections, which can otherwise be reduced with deterioration in oral hygiene.

A wide variety of mouthwashes have been found to have anti-candidal activity, including chlorhexidine gluconate, trichlosan and those incorporating essential oils. Chlorhexidine is a cationic chlorophenyl bisbiguanide and is perhaps the most frequently used mouthwash. Chlorhexidine exhibits a broad spectrum of antimicrobial activity that encompasses Candida species (66). It is believed to bind to negatively charged Candida surfaces, and induces a loss of structural integrity, decreases adherence capability and disrupts the cell wall. Chlorhexidine's anti-candidal properties are also retained against Candida that is adhered to acrylic surfaces (88), and is therefore of value in the treatment of chronic erythematous candidosis. Studies have shown that $0.2 \%$ chlorhexidine gluconate mouth rinses exhibit clinical benefit in the treatment of acute erythematous and pseudomembranous candidosis $(15,30)$. However, there are reports of reduced efficacy of nystatin when used in combination with chlorhexidine gluconate, and therefore it is often advocated that nystatin treatment be delayed for $30 \mathrm{~min}$ after use of chlorhexidine mouthwash. The reason for the reduced efficacy has been proposed to be due to the formation of a low solubility chlorhexidine-nystatin salt that is less effective as an antibiotic agent (10).

Essential oil mouthwashes containing a range of natural plant extracts, including thymol, eucalyptol, bioflavanoids and tea tree (Melaleuca alternifola) oil derivatives, have also been shown to have direct bactericidal and anticandidal activity in vitro (33, 82). It is thought that essential oil mouthwashes kill microorganisms by cell membrane disruption and enzyme inhibition $(34,57)$. As with traditional antifungal agents, however, the effectiveness of natural antimicrobials on established biofilms in the oral cavity is less certain, with incomplete penetration by the agents being reported (76). The clinical efficacy of this category of mouthwashes has been studied, but largely against plaque bacteria $(35,84)$, and therefore the clinical benefits of these agents in treating oral candidosis remain to be established.

One of the main problems associated with eradicating a biofilm from a biomaterial implanted within the body is the difficulty of access for biofilm removal or biomaterial replacement. Often the latter is the only option available for the management of infection of certain indwelling catheters and artificial voice box devices. With regard to dentures, their replacement or removal for thorough cleaning is a relatively easy option. It is essential that dentures are removed during sleep and ideally immersed in a suitable antimicrobial cleansing agent. The mouth rinses described above can all be used, but as the denture is no longer in contact with the host tissues, other chemically harsher cleansers such alkaline and neutral peroxide-type cleansers, hypochlorite, tetrasodium EDTA and acidic solutions may also be employed. Often these agents are used to soak dentures for a defined time period in an immersion bath, thereby allowing the cleansing agent to access areas that are inaccessible by brushing. Prior to use, the dentures are then rinsed in water to remove the treatment agent. Furthermore, water at high temperatures may also be incorporated into the cleaning regime, and the added value of microwaving water-immersed dentures in the treatment of denture stomatitis has also been reported (123). Regular microwaving of dentures, where temperatures approach $100{ }^{\circ} \mathrm{C}$, has been shown to have no adverse affect on the hardness of the denture resins, although increased surface roughness was noted (65).

\section{Future strategies for management of candidal biofilms}

One strategy that has been the focus of recent research is to actually modify the surfaces of biomaterials so that they are less prone to colonization by microorganisms, including Candida (86, 87). Approaches have included pre-coating biomaterials 
such as silicone rubber or denture acrylic with chemicals such as silanes, chlorhexidine, histatins and other surface-modifying groups $(20,87,88)$. In addition, thin-film polymer formulations with incorporated antifungals (nystatin or amphotericin) have also recently been shown to inhibit $C$. albicans biofilm growth on denture materials (93). Such approaches will clearly have value in combating biofilm formation on indwelling medical devices that are not readily accessible for cleaning and physical removal of the biofilm, e.g. artificial voice prostheses (31).

In the future, it may be possible to exploit quorum sensing molecules to disrupt biofilms as they develop, and it has already been shown that farnesol has deleterious effects on Candida biofilms, causing structural instability, even for mature biofilms (48, 92).

Reducing the candidal load within the oral cavity through the use of probiotic agents is also a consideration. Probiotics are live microorganisms that, when administered in adequate amounts, confer a health benefit on the host (70). The concept behind their use in treatment of oral candidosis would be to provide microbiological pressure in the local environment, either through competition for adherence sites and nutrients or by creating an environment that is not conducive to the growth of Candida. There would also appear to be beneficial effects induced by probiotics through immune modulation. Previous studies have used bacterial species such as Streptococcus thermophilus and Lactobacillus bulgaricus to treat biofilms on indwelling voice prostheses (117, 118), and more recently, in the form of cheeses containing probiotic organisms, to reduce Candida load in the oral cavity (42). However, the long-term ability of probiotics to modulate the normal microflora remains unknown.

\section{Conclusion}

Biofilm formation is now a well-recognized phenomenon, and there is clear evidence demonstrating the importance of this life style in human infection. Candida is adept at forming biofilms on a range of surfaces, including natural host tissues and biomaterials frequently used in medical devices. Such biofilms are linked to both systemic and superficial forms of candidosis in humans. New techniques including confocal laser scanning microscopy and molecular analysis tools are enabling elucidation of the control mechanisms underlying biofilm forma- tion. By increasing our knowledge of candidal biofilm formation, potential therapeutic targets may well be identified that can be used as additional therapies, alongside standard oral hygiene practices, in preventing oral candidosis.

\section{References}

1. Abu-Elteen KH, Abu-Alteen RM. The prevalence of Candida albicans populations in the mouths of complete denture wearers. New Microbiol 1998: 21: 41-48.

2. Akpan A, Morgan R. Oral candidiasis. Postgrad Med J 2002: 78: 455-459.

3. Al-Fattani MA, Douglas LJ. Penetration of Candida biofilms by antifungal agents. Antimicrob Agents Chemother 2004: 48: 3291-3297.

4. Al-Fattani MA, Douglas LJ. Biofilm matrix of Candida albicans and Candida tropicalis: chemical composition and role in drug resistance. J Med Microbiol 2006: 55: 9991008.

5. Alem MA, Oteef MD, Flowers TH, Douglas LJ. Production of tyrosol by Candida albicans biofilms and its role in quorum sensing and biofilm development. Eukaryot Cell 2006: 5: 1770-1779.

6. Atkinson BJ, Lewis RE, Kontoyiannis DP. Candida lusitaniae fungemia in cancer patients: risk factors for amphotericin B failure and outcome. Med Mycol 2008: 46: 541-546.

7. Baillie GS, Douglas LJ. Effect of growth rate on resistance of Candida albicans biofilms to antifungal agents. Antimicrob Agents Chemother 1998: 42: 1900-1905.

8. Baillie GS, Douglas LJ. Matrix polymers of Candida biofilms and their possible role in biofilm resistance to antifungal agents. J Antimicrob Chemother 2000: 46: 397403.

9. Barbeau J, Seguin J, Goulet JP, De Koninck L, Avon SL, Lalond B, Rompre P, Deslauries N. Reassessing the presence of Candida albicans in denture-related stomatitis. Oral Surg Oral Med Oral Pathol Oral Radiol Endod 2003: 95: 51-59.

10. Barkvoll P, Attramadal A. Effect of nystatin and chlorhexidine digluconate on Candida albicans. Oral Surg Oral Med Oral Pathol 1989: 67: 279-281.

11. Barnett JA. A history of research on yeasts 12: medical yeasts part 1, Candida albicans. Yeast 2008: 25: 385417.

12. Barrett AW, Kingsmill VJ, Speight PM. The frequency of fungal infection in biopsies of oral mucosal lesions. Oral Dis 1998: 4: 26-31.

13. Bartie KL, Williams DW, Wilson MJ, Potts AJ, Lewis MAO. Differential invasion of Candida albicans isolates in an in vitro model of oral candidosis. Oral Microbiol Immunol 2004: 19: 293-296.

14. Bassetti M, Ansaldi F, Nicolini L, Malfatto E, Molinari MP, Mussap M, Rebesco B, Bobbio Pallavicini F, Icardi G, Viscoli C. Incidence of candidaemia and relationship with fluconazole use in an intensive care unit. $J$ Antimicrob Chemother 2009: 64: 625-629.

15. Budtz-Jorgensen E. Etiology, pathogenesis, therapy, and prophylaxis of oral yeast infections. Acta Odontol Scand 1990: 48: 61-69. 
16. Bulad K, Taylor RL, Verran J, McCord JF. Colonization and penetration of denture soft lining materials by Candida albicans. Dent Mater 2004: 20: 167-175.

17. Campisi G, Panzarella V, Matranga D, Calvino F, Pizzo G, Lo Muzio L, Porter S. Risk factors of oral candidosis: a twofold approach of study by fuzzy logic and traditional statistic. Arch Oral Biol 2008: 53: 388-397.

18. Cardinal E, Braunstein EM, Capello WN, Heck DA. Candida albicans infection of prosthetic joints. Orthopedics 1996: 19: 247-251.

19. Chandra J, Mukherjee PK, Leidich SD, Faddoul FF, Hoyer LL, Douglas LJ, Ghannoum MA. Antifungal resistance of candidal biofilms formed on denture acrylic in vitro. J Dent Res 2001: 80: 903-908.

20. Chandra J, Patel JD, Li J, Zhou G, Mukherjee PK, McCormick TS, Anderson JM, Ghannoum MA. Modification of surface properties of biomaterials influences the ability of Candida albicans to form biofilms. Appl Environ Microbiol 2005: 71: 8795-8801.

21. Chen H, Fujita M, Feng Q, Clardy J, Fink GR. Tyrosol is a quorum sensing molecule in Candida albicans. Proc Natl Acad Sci USA 2004: 101: 5048-5052.

22. Colombo AL, Nucci M, Park BJ, Nouér SA, ArthingtonSkaggs B, Dab Matta DA, Warnock D, Morgan J, Brazilian Network Candidemia Study. Epidemiology of candidemia in Brazil: a nationwide sentinel surveillance of candidemia in eleven medical centers. J Clin Microbiol 2006: 44: 28162823.

23. Corpus K, Hegeman-Dingle R, Bajjoka I. Candida kefyr, an uncommon but emerging fungal pathogen: report of two cases. Pharmacotherapy 2004: 24: 1084-1088.

24. Costerton JW, Cheng KJ, Geesey GG, Ladd TI, Nickel JC, Dasgupta M, Marrie TJ. Bacterial biofilms in nature and disease. Annu Rev Microbiol 1987: 41: 435-464.

25. Costerton JW, Lewandowski Z, Caldwell DE, Korber DR, Lappin-Scott HM. Microbial biofilms. Annu Rev Microbiol 1995: 49: 711-745.

26. Crump JA, Collignon PJ. Intravascular catheter-associated infections. Eur J Clin Microbiol Infect Dis 2000: 19: 1-8.

27. Dongari-Bagtzoglou A. Mucosal biofilms: challenges and future directions. Expert Rev Anti Infect Ther 2008: 6: 141144.

28. Douglas LJ. Candida biofilms and their role in infection. Trends Microbiol 2003: 11: 30-36.

29. Egusa H, Soysa NS, Ellepola AN, Yatani H, Samaranayake LP. Oral candidosis in HIV-infected patients. Curr HIV Res 2008: 6: 485-499.

30. Ellepola ANB, Samaranayake LP. Oral candidal infections and antimycotics. Crit Rev Oral Biol Med 2000: 11: 172198.

31. Everaert EP, Mahieu HF, Van de Belt-Gritter B, Peeters AJ, Verkerke GJ, Van der Mei HC, Busscher HJ. Biofilm formation in vivo on perfluoro-alkylsiloxane-modified voice prostheses. Arch Otolaryngol Head Neck Surg 1999: 125: 1329-1332.

32. Figueiral MH, Azul A, Pinto E, Fonseca PA, Branco FM, Scully C. Denture-related stomatitis: identification of aetiological and predisposing factors - a large cohort. J Oral Rehabil 2007: 34: 448-455.

33. Filoche SK, Soma K, Sissons CH. Antimicrobial effects of essential oils in combination with chlorhexidine digluconate. Oral Microbiol Immunol 2005: 20: 221-225.
34. Fine DH. Mouthrinses as adjuncts for plaque and gingivitis management. A status report for the American Journal of Dentistry. Am J Dent 1988: 1: 259-263.

35. Fine DH, Markowitz K, Furgang D, Goldsmith D, Charles $\mathrm{CH}$, Lisante TA, Lynch MC. Effect of an essential oil-containing antimicrobial mouthrinse on specific plaque bacteria in vivo. J Clin Periodontol 2007: 34: 652657.

36. Fukushima C, Matsuse H, Saeki S, Kawano T, Machida I, Kondo Y, Kohno S. Salivary IgA and oral candidiasis in asthmatic patients treated with inhaled corticosteroid. J Asthma 2005: 42: 601-604.

37. Fukushima C, Matsuse H, Tomari S, Obase Y, Miyazaki Y, Shimoda T, Kohno S. Oral candidiasis associated with inhaled corticosteroid use: comparison of fluticasone and beclomethasone. Ann Allergy Asthma Immunol 2003: 90: 646-651.

38. Geerts GAVM, Stuhlinger ME, Basson NJ. Effect of an antifungal denture liner on the saliva yeast count in patients with denture stomatitis: a pilot study. J Oral Rehab 2008: 35: 664-669.

39. González GM, Elizondo M, Ayala J. Trends in species distribution and susceptibility of bloodstream isolates of Candida collected in Monterrey, Mexico, to seven antifungal agents: results of a 3-year (2004 to 2007) surveillance study. J Clin Microbiol 2008: 46: 2902-2905.

40. Grbic JT, Mitchell-Lewis DA, Fine JB, Phelan JA, Bucklan RS, Zambon JJ, Lamster IB. The relationship of candidiasis to linear gingival erythema in HIV-infected homosexual men and parenteral drug users. J Periodontol 1995: 66: 3037.

41. Hajjeh RA, Sofair AN, Harrison LH, Lyon GM, ArthingtonSkaggs BA, Mirza SA, Phelan M, Morgan J, Lee-Yang W, Ciblak MA, Benjamin LE, Sanza LT, Huie S, Yeo SF, Brandt ME, Warnock DW. Incidence of bloodstream infections due to Candida species and in vitro susceptibilities of isolates collected from 1998 to 2000 in a population-based active surveillance program. J Clin Microbiol 2004: 42: 1519-1527.

42. Hatakka K, Ahola AJ, Yli-Knuuttila H, Richardson M, Poussa T, Meurman JH, Korpela R. Probiotics reduce the prevalence of oral Candida in the elderly - a randomized controlled trial. J Dent Res 2007: 86: 125-130.

43. Hawser SP, Douglas LJ. Resistance of Candida albicans biofilms to antifungal agents in vitro. Antimicrob Agents Chemother 1995: 39: 2128-2131.

44. Hazen KC, Theisz GW, Howell SA. Chronic urinary tract infection due to Candida utilis. J Clin Microbiol 1999: 37: 824-827.

45. Hope CK, Wilson M. Effects of dynamic fluid activity from an electric toothbrush on in vitro oral biofilms. J Clin Periodontol 2003: 30: 624-629.

46. Horn DL, Neofytos D, Anaissie EJ, Fishman JA, Steinbach WJ, Olyaei AJ, Marr KA, Pfaller MA, Chang CH, Webster KM. Epidemiology and outcomes of candidemia in 2019 patients: data from the prospective antifungal therapy alliance registry. Clin Infect Dis 2009: 48: 16951703.

47. Hornby JM, Jensen EC, Lisec AD, Tasto JJ, Jahnke B, Shoemaker R, Dussault P, Nickerson KW. Quorum sensing in the dimorphic fungus Candida albicans is mediated by farnesol. Appl Environ Microbiol 2001: 67: 2982-2992. 
48. Jabra-Rizk MA, Shirtliff M, James C, Meiller T. Effect of farnesol on Candida dubliniensis biofilm formation and fluconazole resistance. FEMS Yeast Res 2006: 6: 1063-1073.

49. Jain N, Kohli R, Cook E, Gialanella P, Chang T, Fries BC. Biofilm formation by and antifungal susceptibility of Candida isolates from urine. Appl Environ Microbiol 2007: 73: 1697-1703.

50. Jayatilake JA, Samaranayake YH, Cheung LK, Samaranayake LP. Quantitative evaluation of tissue invasion by wild type, hyphal and SAP mutants of Candida albicans, and non-albicans Candida species in reconstituted human oral epithelium. J Oral Pathol Med 2006: 35: 484-491.

51. Khardori N, Yassien M. Biofilms in device-related infections. J Ind Microbiol 1995: 15: 141-147.

52. Kim MN, Shin JH, Sung H, Lee K, Kim EC, Ryoo N, Lee JS, Jung SI, Park KH, Kee SJ, Kim SH, Shin MG, Suh SP, Ryang DW. Candida haemulonii and closely related species at 5 university hospitals in Korea: identification, antifungal susceptibility, and clinical features. Clin Infect Dis 2009: 48: e57-e61.

53. Kimura LH, Pearsall NN. Relationship between germination of Candida albicans and increased adherence to human buccal epithelial cells. Infect Immun 1980: 28: 464468.

54. Kornman KS. Diagnostic and prognostic tests for oral diseases: practical applications. J Dent Educ 2005: 69: 498508.

55. Krcméry V, Barnes AJ. Non-albicans Candida spp. causing fungaemia: pathogenicity and antifungal resistance. J Hosp Infect 2002: 50: 243-260.

56. Krcméry V, Kunová A. Candida famata fungemia in a cancer patient: case report. J Chemother 2000: 12: 189-190.

57. Kubert D, Rubin M, Barnett ML, Vincent JW. Antiseptic mouthrinse-induced microbial cell surface alterations. $\mathrm{Am}$ J Dent 1993: 6: 277-279.

58. Kuriyama T, Williams DW, Lewis MAO. In vitro secreted aspartyl proteinase activity of Candida albicans isolated from oral diseases and healthy oral cavities. Oral Microbiol Immunol 2003: 18: 405-407.

59. LaFleur MD, Kumamoto CA, Lewis K. Candida albicans biofilms produce antifungal-tolerant persister cells. Antimicrob Agents Chemother 2006: 50: 3839-3846.

60. Lass-Flörl C. The changing face of epidemiology of invasive fungal disease in Europe. Mycoses 2009: 52: 197205.

61. Leonhardt A, Renvert S, Dahlén G. Microbial findings at failing implants. Clin Oral Implants Res 1999: 10: 339-345.

62. Leroy O, Gangneux JP, Montravers P, Mira JP, Gouin F, Sollet JP, Carlet J, Reynes J, Rosenheim M, Regnier B, Lortholary O, AmarCand Study Group. Epidemiology, management, and risk factors for death of invasive Candida infections in critical care: a multicenter, prospective, observational study in France (2005-2006). Crit Care Med 2009: 37: 1612-1618.

63. Li L, Redding S, Dongari-Bagtzoglou A. Candida glabrata: an emerging oral opportunistic pathogen. J Dent Res 2007: 86: $204-215$.

64. Liguori G, Di Onofrio V, Lucariello A, Gallé F, Signoriello G, Colella G, D’Amora M, Rossano F. Oral candidiasis: a comparison between conventional methods and multiplex polymerase chain reaction for species identification. Oral Microbiol Immunol 2009: 24: 76-78.
65. Machado A, Breeding L, Vergani C, da Cruz Perez L. Hardness and surface roughness of reline and denture base acrylic resins after repeated disinfection procedures. J Prosthet Dent 2009: 102: 115-122.

66. MacNeill S, Rindler E, Walker A, Brown AR, Cobb CM. Effects of tetracycline hydrochloride and chlorhexidine gluconate on Candida albicans: an in vitro study. J Clin Periodontol 1997: 24: 753-760.

67. Malic S, Hill KE, Ralphs JR, Hayes A, Thomas DW, Potts AJ, Williams DW. Characterization of Candida albicans infection of an in vitro oral epithelial model using confocal laser scanning microscopy. Oral Microbiol Immunol 2007: 22: 188-194.

68. Martins M, Henriques M, Azeredo J, Rocha SM, Coimbra MA, Oliveira R. Morphogenesis control in Candida albicans and Candida dubliniensis through signaling molecules produced by planktonic and biofilm cells. Eukaryot Cell 2007: 6: 2429-2436.

69. Mateus C, Crow SA Jr, Ahearn DG. Adherence of Candida albicans to silicone induces immediate enhanced tolerance to fluconazole. Antimicrob Agents Chemother 2004: 48: 3358-3366.

70. Meurman JH. Probiotics: do they have a role in oral medicine and dentistry? Eur J Oral Sci 2005: 113: 188-196.

71. Miranda LN, Van der Heijden IM, Costa SF, Sousa AP, Sienra RA, Gobara S, Santos CR, Lobo RD, Pessoa VP Jr, Levin AS. Candida colonisation as a source for candidaemia. J Hosp Infect 2009: 72: 9-16.

72. Mokaddas EM, Al-Sweih NA, Khan ZU. Species distribution and antifungal susceptibility of Candida bloodstream isolates in Kuwait: a 10-year study. J Med Microbiol 2007: 56: 255-259.

73. Mukherjee PK, Chandra J, Kuhn DM, Ghannoum MA. Mechanism of fluconazole resistance in Candida albicans biofilms: phase-specific role of efflux pumps and membrane sterols. Infect Immun 2003: 71: 4333-4440.

74. Nair PN, Sjögren U, Krey G, Kahnberg KE, Sundqvist G. Intraradicular bacteria and fungi in root-filled, asymptomatic human teeth with therapy-resistant periapical lesions: a long-term light and electron microscopic followup study. J Endod 1990: 16: 580-588.

75. Nett JE, Lepak AJ, Marchillo K, Andes DR. Time course global gene expression analysis of an in vivo Candida biofilm. J Infect Dis 2009: 200: 307-313.

76. Netuschil L, Weiger R, Preisler R, Brecx M. Plaque bacteria counts and vitality during chlorhexidine, meridol and listerine mouthrinses. Eur J Oral Sci 1995: 103: 355-361.

77. Nickerson KW, Atkin AL, Hornby JM. Quorum sensing in dimorphic fungi: farnesol and beyond. Appl Environ Microbiol 2006: 72: 3805-3813.

78. Nobile CJ, Schneider HA, Nett JE, Sheppard DC, Filler SG, Andes DR, Mitchell AP. Complementary adhesin function in C. albicans biofilm formation. Curr Biol 2008: 18: 10171024.

79. Odds FC. Candida and Candidosis, 2nd Edn. London: Bailliere Tindall, 1988.

80. Odds FC. Pathogenesis of Candida infections. J Am Acad Dermatol 1994: 31: S2-S5.

81. Olsen I. Denture stomatitis, occurrence and distribution of fungi. Acta Odontol Scand 1974: 32: 329-333.

82. Pan PH, Finnegan MB, Sturdivant L, Barnett ML. Comparative antimicrobial activity of an essential oil and an 
amine fluoride/stannous fluoride mouthrinse in vitro. J Clin Periodontol 1999: 26: 474-476.

83. Parahitiyawa NB, Samaranayake YH, Samaranayake LP, Ye J, Tsang PW, Cheung BP, Yau JY, Yeung SK. Interspecies variation in Candida biofilm formation studied using the Calgary biofilm device. APMIS 2006: 114: 298306.

84. Pizzo G, La Cara M, Licata ME, Pizzo I, D’Angelo M. The effects of an essential oil and an amine fluoride/stannous fluoride mouthrinse on supragingival plaque regrowth. J Periodontol 2008: 79: 1177-1183.

85. Pfaller MA, Diekema DJ. Epidemiology of invasive candidiases: a persistent public health problem. Clin Microbiol Rev 2007: 20: 133-163.

86. Price CL, Waters MG, Williams DW, Lewis MAO, Stickler D. Surface modification of an experimental silicone rubber aimed at reducing initial candidal adhesion. $J$ Biomed Mater Res 2002: 63: 122-128.

87. Price CL, Williams DW, Waters MG, Coulthwaite L, Verran J, Taylor RL, Stickler D, Lewis MAO. Reduced adherence of Candida to silane-treated silicone rubber. J Biomed Mater Res B Appl Biomater 2005: 74: 481-487.

88. Pusateri CR, Monaco EA, Edgerton M. Sensitivity of Candida albicans biofilm cells grown on denture acrylic to antifungal proteins and chlorhexidine. Arch Oral Biol 2009: 54: 588-594.

89. Radfar L, Shea Y, Fischer SH, Sankar V, Leakan RA, Baum BJ, Pillemer SR. Fungal load and candidiasis in Sjögren's syndrome. Oral Surg Oral Med Oral Pathol Oral Radiol Endod 2003: 96: 283-287.

90. Ramage G, Martínez JP, López-Ribot JL. Candida biofilms on implanted biomaterials: a clinically significant problem. FEMS Yeast Res 2006: 6: 979-986.

91. Ramage G, Saville PS, Thomas PD, López-Ribot JL. Candida biofilms: an update. Eukaryot Cell 2005: 4: 633-638.

92. Ramage G, VandeWalle K, Bachmann SP, Wickes BL, Lopez-Ribot JL. In vitro pharmacodynamic properties of three antifungal agents against preformed Candida albicans biofilms determined by time-kill studies. Antimicrob Agents Chemother 2002: 46: 3634-3636.

93. Redding S, Bhatt B, Rawls HR, Siegel G, Scott K, LopezRibot J. Inhibition of Candida albicans biofilm formation on denture material. Oral Surg Oral Med Oral Pathol Oral Radiol Endod 2009: 107: 669-672.

94. Renstrup G. Occurrence of Candida in oral leukoplakias. Acta Pathol Microbiol Scand B Microbiol Immunol 1970: 78: 421-424.

95. Rüping MJ, Vehreschild JJ, Cornely OA. Patients at high risk of invasive fungal infections: when and how to treat. Drugs 2008: 68: 1941-1962.

96. Salamon SA, Fuursted K, Egeblad H, Petersen E, Ott P. Candida albicans tricuspid and pulmonic valve endocarditis: challenge of relapsing risk and role of combined medical treatment and surgery. Scand J Infect Dis 2007: 39: 641-644.

97. Salles AES, Macedo LD, Fernandes RAG, Silva-Lovato CH, Paranhos HdeFO. Comparative analysis of biofilm levels in complete upper and lower dentures after brushing associated with specific denture paste and neutral soap. Gerodontology 2007: 24: 217-223.

98. Sakashita S, Takayama K, Nishioka K, Katoh T. Taste disorders in healthy 'carriers' and 'non-carriers' of Candida albicans and in patients with candidosis of the tongue. J Dermatol 2004: 31: 890-897.

99. Samaranayake LP. Superficial oral fungal infections. Curr Opin Dent 1991: 1: 415-422.

100. Samaranayake LP. Nutritional factors and oral candidosis. J Oral Pathol 1986: 15: 61-65.

101. Samaranayake LP, Keung Leung W, Jin L. Oral mucosal fungal infections. Periodontol 2000 2009: 49: 39-59.

102. Samaranayake LP, Lamb AB, Lamey PJ, MacFarlane TW. Oral carriage of Candida species and coliforms in patients with burning mouth syndrome. J Oral Pathol Med 1989: 18: 233-235.

103. Samaranayake LP, MacFarlane TW. Factors affecting the in-vitro adherence of the fungal oral pathogen Candida albicans to epithelial cells of human origin. Arch Oral Biol 1982: 27: 869-873.

104. Samaranayake YH, Samaranayake LP. Candida krusei: biology, epidemiology, pathogenicity and clinical manifestations of an emerging pathogen. J Med Microbiol 1994: 41: 295-310.

105. Sanglard D, Ischer F, Marchetti O, Entenza J, Bille J. Calcineurin A of Candida albicans: involvement in antifungal tolerance, cell morphogenesis and virulence. Mol Microbiol 2003: 48: 959-976.

106. Shchepin R, Hornby JM, Burger E, Niessen T, Dussault $\mathrm{P}$, Nickerson KW. Quorum sensing in Candida albicans: probing farnesol's mode of action with 40 natural and synthetic farnesol analogs. Chem Biol 2003: 10: 743750 .

107. Shimizu C, Kuriyama T, Williams DW, Karasawa T, Inoue K, Nakagawa K, Yamamoto E. Association of oral yeast carriage with specific host factors and altered mouth sensation. Oral Surg Oral Med Oral Pathol Oral Radiol Endod 2008: 105: 445-451.

108. Shin JH, Kook H, Shin DH, Hwang TJ, Kim M, Suh SP, Ryang DW. Nosocomial cluster of Candida lipolytica fungemia in pediatric patients. Eur J Clin Microbiol Infect Dis 2000: 19: 344-349.

109. Sitheeque MA, Samaranayake LP. Chronic hyperplastic candidosis / candidiasis (candidal leukoplakia). Crit Rev Oral Biol Med 2003: 14: 253-267.

110. Smith AJ, Robertson D, Tang MK, Jackson MS, MacKenzie D, Bagg J. Staphylococcus aureus in the oral cavity: a threeyear retrospective analysis of clinical laboratory data. Br Dent J 2003: 195: 701-703.

111. Soysa NS, Samaranayake LP, Ellepola AN. Diabetes mellitus as a contributory factor in oral candidosis. Diabet Med 2006: 23: 455-459.

112. Soysa NS, Samaranayake LP, Ellepola AN. Antimicrobials as a contributory factor in oral candidosis - a brief overview. Oral Dis 2008: 14: 138-143.

113. Sugar AM, Stevens DA. Candida rugosa in immunocompromised infection: case reports, drug susceptibility and review of the literature. Cancer 1985: 56: 318-320.

114. Sullivan DJ, Moran GP, Coleman DC. Candida dubliniensis: ten years on. FEMS Microbiol Lett 2005: 253: 9-17.

115. Trofa D, Gácser A, Nosanchuk JD. Candida parapsilosis, an emerging fungal pathogen. Clin Microbiol Rev 2008: 21: 606-625.

116. Tumbarello M, Posteraro B, Trecarichi EM, Fiori B, Rossi M, Porta R, De Gaetano Donati K, La Sorda M, Spanu T, Fadda G, Cauda R, Sanguinetti M. Biofilm production by 
Candida species and inadequate antifungal therapy as predictors of mortality for patients with candidemia. J Clin Microbiol 2007: 45: 1843-1850.

117. Van der Mei HC, Free RH, Elving GJ, Van Weissenbruch R, Albers FW, Busscher HJ. Effect of probiotic bacteria on prevalence of yeasts in oropharyngeal biofilms on silicone rubber voice prostheses in vitro. J Med Microbiol 2000: 49: 713-718.

118. Van Weissenbruch R, Bouckaert S, Remon JP, Nelis HJ, Aerts R, Albers FW. Chemoprophylaxis of fungal deterioration of the Provox silicone tracheoesophageal prosthesis in postlaryngectomy patients. Ann Otol Rhinol Laryngol 1997: 106: 329-337.

119. Velegraki A, Nicolatou O, Theodoridou M, Mostrou G, Legakis NJ. Paediatric AIDS-related linear gingival erythema: a form of erythematous candidiasis? J Oral Pathol Med 1999: 28: 178-182.

120. Verran J, Maryan CJ. Retention of Candida albicans on acrylic resin and silicone of different surface topography. J Prosthet Dent 1997: 77: 535-539.

121. Vuong C, Kocianova S, Voyich JM, Yao Y, Fischer ER, DeLeo FR, Otto M. A crucial role for exopolysaccharide modification in bacterial biofilm formation, immune evasion, and virulence. J Biol Chem 2004: 279: 5488154886.

122. Walker DM, Arendorf T. Oral candidosis. In: Samaranayake LP, MacFarlane TW editors. Candidal Leukoplakia, Chronic Multifocal Candidosis and Median Rhomboid Glossitis. London: Wright, 1990: 184-199.

123. Webb BC, Thomas CJ, Whittle T. A 2-year study of Candida associated denture stomatitis treatment in aged care subjects. Gerodontology 2005: 22: 168-176.

124. Weerasuriya N, Snape J. Oesophageal candidiasis in elderly patients: risk factors, prevention and management. Drugs Aging 2008: 25: 119-130.

125. Williams DW, Potts AJ, Wilson MJ, Matthews JB, Lewis MAO. Characterisation of the inflammatory cell infiltrate in chronic hyperplastic candidosis of the oral mucosa. J Oral Pathol Med 1997: 26: 83-89.

126. Yeater KM, Chandra J, Cheng G, Mukherjee PK, Zhao X, Rodriguez-Zas SL, Kwast KE, Ghannoum MA, Hoyer LL. Temporal analysis of Candida albicans gene expression during biofilm development. Microbiology 2007: 153: 2373-2385. 